\title{
Endoparasites in European hares (Lepus europaeus) under gamekeeping conditions in the Czech Republic
}

\author{
D. LUKEŠOVÁ ${ }^{1 *}$, I. LANGROVÁ ${ }^{2}$, J. VADLEJCH $^{2}$, I. JANKOVSKÁ ${ }^{2}$, J. HLAVA $^{2}$, P. VÁLEK $^{2}$, Z. ČADKOVÁ ${ }^{2}$
}

\author{
${ }^{1}$ Department of Animal Science and Food Processing in the Tropics and Subtropics, Institute of Tropics and \\ Subtropics, Czech University of Life Sciences, 16521 Prague 6 - Suchdol, Czech Republic, \\ "E-mail: lukesd@its.czu.cz; ${ }^{2}$ Department of Zoology and Fisheries, Faculty of Agrobiology, Food and Natural \\ Resources, Czech University of Life Sciences Prague, Kamýcká 957, 16521 Prague 6 - Suchdol, Czech Republic
}

\begin{abstract}
Summary
During December 2007 and November - April 2008/2009, 128 gastrointestinal tracts and 1680 faecal samples of hares from different parts of the Czech Republic were examined. Evaluation of the faeces samples indicated that the samples could have been infected with any one of the following parasites: Eimeria spp., Trichostrongylus retortaeformis, Trichuris leporis, Graphidium strigosum, Strongyloides sp., Protostrongylus spp. and Anoplocephalidae tapeworms. Trichostrongylus retortaeformis was the most common nematode $(75.8 \%) .39 .8 \%$ of the animals were infected with Trichuris leporis. Only four hares were infected with Graphidium strigosum. Eimeria spp. was the most commonly occurring parasite $(90.5 \%)$. The following species were found: Eimeria coquelinae, E. cabareti, E. leporis, E. babatica, E. europea, E. pierrecouderti, E. macrosculpta, E. orbiculata and E. stefanski. Eimeria coquelinae was the most prevalent species $(68.4 \%)$. Eimeria cabareti and E. leporis were the next most frequently found species ( $64.5 \%$ and $57.8 \%$, respectively).
\end{abstract}

Keywords: European hare; Central Europe; endoparasites; prevalence; seasonal dynamics

\section{Introduction}

Reports on endoparasites in hares are sporadic (especially recently), with none whatsoever from the region of Central Europe. Moreover, hares in the Czech Republic live almost exclusively in areas kept by game keeping organizations. These organizations provide the animals with supplementary feed and treat their illnesses in winter. In autumn, certain specimens are permitted to be shot.

Hares in Central Europe are traditional game animals, which usually occur in Europe in abundant numbers (Strauss et al., 2008; Fettinger et al., 2010). Unfortunately their counts in the Czech Republic have been dropping in recent times. There are several causes, but the main rea- sons are changes in rural landscape and general changes in agriculture. A number of game keeping organizations take very good care of their hares because they are traditionally a very popular game animal. At their suggestion, we investigated current parasitary conditions of these animals.

Many studies of the endoparasites of European hares were conducted in the latter half of the twentieth century (Haupt \& Hartung, 1976; Kutzer \& Frey, 1976; Nickel \& Gottwald, 1979; Forstner \& Ilg, 1982; Soveri \& Valtonen, 1983; Pakandl, 1990; Allgöwer, 1992; Böckeler et al., 1994). Recently, studies have become rarer i.e., from France by Bordes et al. (2007), from Poland by Pilarczyk et al. (2008) and from Slovakia by Dubinský et al. (2010).

The objectives of this study were as follows: 1) to observe the prevalence and abundance of gastrointestinal (GI) parasites of European hares in game keeping shooting-ground conditions during two winter seasons, 2) to monitor seasonal dynamics of exogenous stage excretion during the winter and spring season. 3) to evaluate the importance of parasites for hares in the Czech Republic.

\section{Materials and methods}

Parasite data came primarily from 128 hares shot dead during December 2007 and December - January 2008/2009, always from 8 localities (game keeper areas). The localities stretched from the lowlands of intensive agriculture (landscape dominated by fields) to the highlands.

The size of the gamekeeping areas ranged from 750 ha to 1860 ha, with forest-covered areas ranging from $1.5 \%$ to $37.4 \%$ (highlands). Altitudes were from 184 to $610 \mathrm{~m}$.

During the slaughtering periods, hunters were asked to collect the GI tract from hares from different parts of the Czech Republic, and send them to the Section of Parasitology, Czech University of Life Sciences Prague. Furthermore, the faecal samples were collected from the same 8 
Table 1. Prevalence and intensity of parasitism among hares (Lepus europaeus) in the Czech Republic

\begin{tabular}{lcccc}
\hline Parasite & Number & Percentage of & \multicolumn{2}{c}{ Intensity } \\
\cline { 4 - 5 } & infected & infection (\%) & Mean \pm SD & Range \\
\hline Trichostrongylus retortaeformis & 97 & 75.8 & $158.9 \pm 377.3$ & $4-2691$ \\
Trichuris leporis & 51 & 39.8 & $13.4 \pm 12.9$ & $1-47$ \\
Graphidium strigosum & 4 & 3.9 & $1.5 \pm 0.6$ & $1-2$ \\
\hline
\end{tabular}

localities (400 samples during December 2007, 160 samples each month from November 2008 to April 2009).

The viscera (abomasum, small intestines colon and caecum) of all hares were collected and processed for worm recovery, enumeration and identification by the methods described by Eysker and Kooyman (1993).
The Eimeria oocysts were determined using the descriptions of Pellérdy (1956), Bouvier (1967), Levine and Ivens (1972), Pakandl (1990) and Aoutil et al. (2005).

Statistical analysis of data was conducted by the statistical program Statistica.cz (StatSoft USA, ANOVA, POSTHOC test).

Table 2. Parasite faecal stage excretion in hares (Lepus europaeus) in the Czech Republic

\begin{tabular}{lcccc}
\hline Parasite & Number & Individual & \multicolumn{2}{c}{ Intensity* } \\
\cline { 5 - 5 } & sf faecal & sositive faecal & Mean \pm SD & Range \\
& 800 & 90.5 & $593.0 \pm 881.8$ & $4-9226$ \\
\hline Eimeria spp. & 800 & 88.2 & $121.8 \pm 380.1$ & $4-1045$ \\
Trichostrongylus retortaeformis & 800 & 7.3 & $11.9 \pm 10.6$ & $4-38.5$ \\
Graphidium strigosum & 800 & 19.2 & $40.5 \pm 63.1$ & $4-98$ \\
Trichuris leporis & 800 & 6.5 & $14.3 \pm 11.6$ & $4-27$ \\
Strongyloides spp. & 800 & 25.7 & $19.8 \pm 75.5$ & $4-423.5$ \\
Protostrongylus spp. & 800 & 0.87 & $7.5 \pm 6.2$ & $4-21$ \\
Anoplocephalidae & & & & \\
\hline
\end{tabular}

*eggs/oocysts/larvae per gram of faeces

The faecal samples were stored in plastic tubes at $4{ }^{\circ} \mathrm{C}$ for a week prior to analysis. All the samples from the hares were examined individually for GI nematode eggs and coccidian oocysts using the modified Breza flotation solution $\left(\mathrm{Na}_{2} \mathrm{~S}_{2} \mathrm{O}_{3}\right.$ and $\mathrm{MgSO}_{4}$ with specific gravity 1.35 g.cm $\left.{ }^{-3}\right)$ and McMaster method (Wetzel, 1951). A Baermann apparatus was used to separate $1^{\text {st }}$ stage lungworm larvae from faecal samples. Cryptosporidium spp. was detected by means of the Miláček and Vítovec method (1985).

Isolated oocysts, eggs and larvae were investigated using an Olympus BX41microscope. Oocysts were measured using an integrated computerized system, and photographed with an Olympus SP-350 digital camera mounted on an Olympus BX41microscope using phase contrast imaging with a $100 \mathrm{x}$ objective oil immersion lens.

Eggs, $\mathrm{L}_{1}$ larva and adult helminth parasites were determined according to Levine (1980) and Kotrlá et al. (1984).

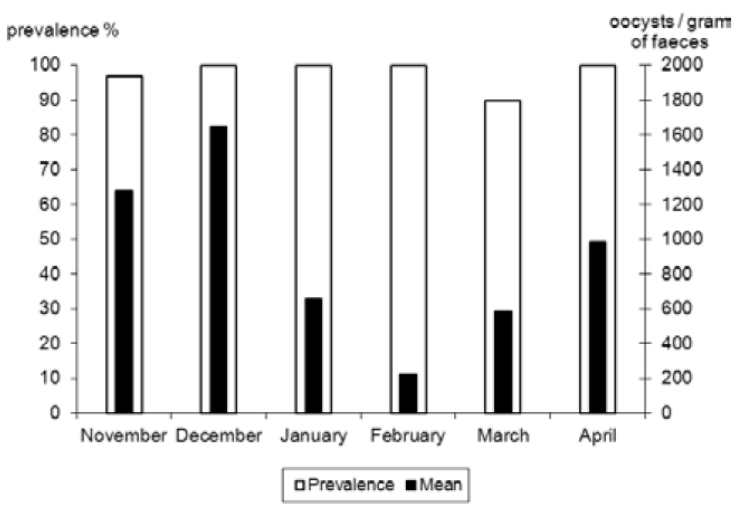

Fig. 1. Seasonal dynamics of exogenous parasitic stage excretion 160 in feces - Eimeria

\section{Results}

Three species of parasites were identified in the GI tracts of 128 hares examined: Trichostrongylus retortaeformis, Trichuris leporis and Graphidium strigosum. Passalurus ambiguous, Strongyloides sp. and tapeworms were not found in the intestines of the examined hares.

T. retortaeformis was the most common nematode (97 animals positive, $75.8 \%), 39.8 \%(\mathrm{n}=51)$ of the animals infected with Trichuris leporis. Only four hares were infected with Graphidium strigosum. The mean intensity of infection with $T$. retortaeformis was $158.9(4-2691)$, with T. leporis $13.4(1-47)$ - Table 1 .

Significant differences in gender parasite distribution were not detected $(\mathrm{p} \geq 0.05)$. Gastrointestinal parasites in hare excretion are shown in Table 2. Evaluation of the faeces samples indicated that they could have been infected with

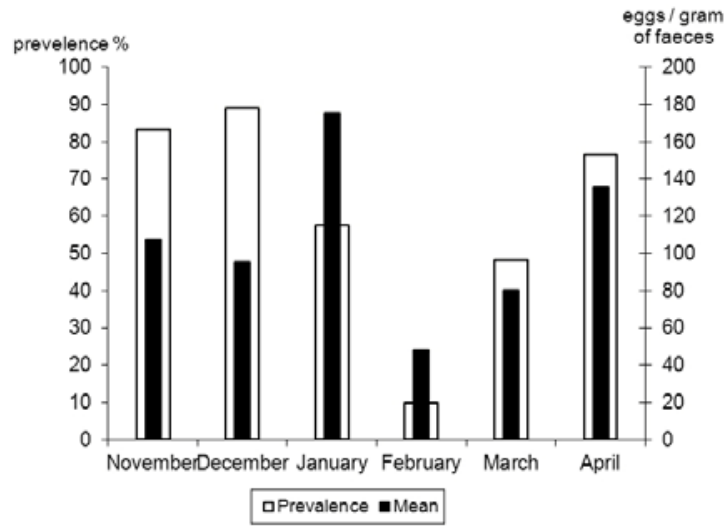

Fig. 2. Seasonal dynamics of exogenous parasitic stage excretion in feces - Trichostrongylus sp. 


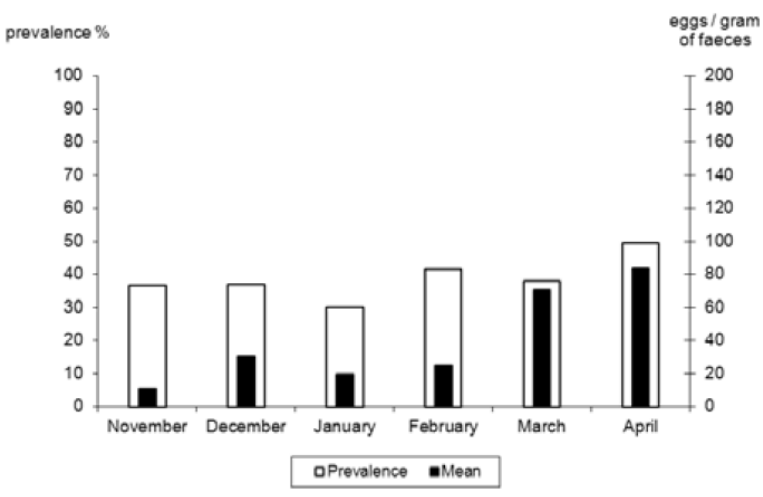

Fig. 3. Seasonal dynamics of exogenous parasitic stage excretion in feces - Trichuris sp.

any one of the following parasites: Eimeria spp., Trichostrongylus retortaeformis, Trichuris leporis, Graphidium strigosum, Strongyloides sp., Protostrongylus spp. and Anoplocephalidae tapeworms.

Eimeria spp. was the most commonly occurring parasite being recorded from hare faeces $(90.5 \%$ faecal samples), followed by $T$. retortaeformis $(88.2 \%)$ and $T$. leporis (19.2\%) - Table 2. Anoplocephalidae showed the lowest prevalence and intensity of the exogenous stages - eggs $(0.87 \%)$ cabareti and E. leporis were the next most frequently found species. They occurred in 64.5 and $57.8 \%$ of the samples, respectively. Other species were found in $39.5 \%$ or less of the samples. Eimeria stefanski was the most infrequently occurring species (Table 3 ).

Cryptosporidium spp. was detected in 5 of the 360 examined faecal samples of hares. In the current study, no significant differences in hare parasite infection among all localities were discovered ( $\mathrm{p} \geq 0.05)$.

\section{Discussion}

The hare is an important game animal in the Czech Republic. Generally we take the indigenous population into account. Although in some areas, animals were released that had been previously caught in neighbouring countries (i.e. Hungary). The population of wild rabbits, which could affect parasites in hares, is currently negligible in the Czech Republic.

The parasite species community of the Czech game hare is very limited, only three species of nematodes were recorded in the GI tracts of game hares in the Czech Republic: Trichostrongylus retortaeformis, Trichuris leporis and Graphidium strigosum. Both Passalurus ambiguus and tapeworms were not observed.

Table 3. Eimeria faecal oocyst excretion in hares (Lepus europaeus) in the Czech Republic

\begin{tabular}{lcccc}
\hline \multicolumn{1}{c}{ Parasite species } & $\begin{array}{c}\text { Number of } \\
\text { faecal } \\
\text { samples }\end{array}$ & $\begin{array}{c}\text { Individual } \\
\text { positive } \\
\text { faecal } \\
\text { samples (\%) }\end{array}$ & $\begin{array}{c}\text { Intensity } \\
\text { Mean } \pm \text { SD }\end{array}$ & Range \\
\hline Eimeria coquelinae & 800 & 68.4 & $521.2 \pm 823.2$ & $7-4393$ \\
Eimeria cabareti & 800 & 64.5 & $318.7 \pm 519.3$ & $18-3948$ \\
Eimeria leporis & 800 & 57.8 & $203.6 \pm 380.1$ & $7-2236$ \\
Eimeria babatica & 800 & 39.5 & $47.2 \pm 69.6$ & $4-287$ \\
Eimeria europea & 800 & 34.7 & $22.8 \pm 36.6$ & $7-178$ \\
Eimeria pierrcouderti & 800 & 15.9 & $34.4 \pm 52.4$ & $4-287$ \\
Eimeria macrosculpta & 800 & 7.3 & $10.6 \pm 18.3$ & $4-123$ \\
Eimeria orbiculata & 800 & 8.3 & $10.1 \pm 12.5$ & $4-56$ \\
Eimeria stefanski & 800 & 1.8 & $7.4 \pm 14.4$ & $4-59$ \\
\hline
\end{tabular}

Seasonal dynamics of exogenous parasitic stage excretion in feces are given in Figs 1 to 3. A significant decrease in the intensity of the Eimeria oocyst excretion was observed in January and, in particular, February (660.5 \pm 797.5 , $224.4 \pm 228.1$ respectively). A decline in the prevalence and intensity of egg excretion in February was also observed for Trichostrongylus retortaeformis $(9.8 \%, 47.9 \pm$ 110). The presence of Trichuris eggs in the feces increased in the spring (in April - 49.5\%, average EPG 83.5 \pm 49.3 ). Nine different species of Eimeria were identified from 800 faecal samples of hares collected from 8 shooting-grounds in the Czech Republic: Eimeria coquelinae, E. cabareti, E. leporis, E. babatica, E. europea, E. pierrecouderti, E. macrosculpta, E. orbiculata and E. stefanski. The species detection and prevalence rates are given in Table 3. Eimeria coquelinae, which occured in $68.4 \%$ of the samples, was the most prevalent species among the hares. Eimeria
In the present study, as well as in surrounding countries, $T$. retortaeformis was the most common species. Studies from surrounding European countries showed that infection varies from $75.8 \%$ to $96.8 \%$ (Haupt \& Hartung, 1976; Kutzer \& Frey, 1976; Forstner \& Ilg, 1982; Allgöwer, 1992). A lower prevalence from Finland was reported by Soveri and Valtonen (1983) (54.2\%) and a very low prevalence was reported from Belarus by Shimalov (2001) $18.2 \%$. The occurrence of $T$. retortaeformis is largely determined by appropriate environmental conditions in Central Europe. Only when temperatures drop below $10{ }^{\circ} \mathrm{C}$, does exogenous development cease (Crofton, 1946). The second most important nematodes of hares is T. leporis. The prevalence from other European countries was found to range between 13.2\% (Belarus - Shimalov, 2001) to $66.7 \%$ (Germany - Haupt \& Hartung, 1976). In agreement to the many reports from surrounding European 


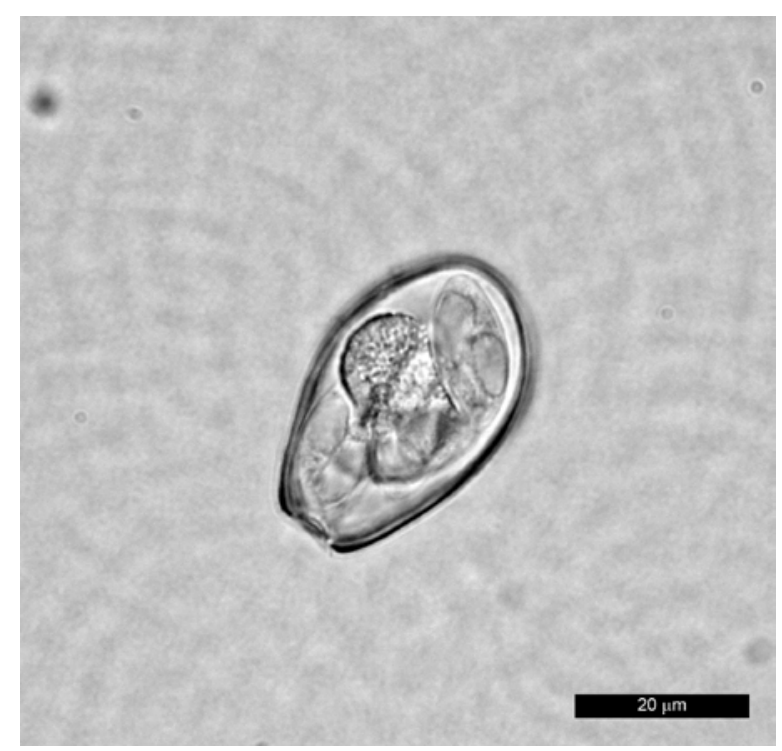

Fig. 4. The photomicrograph of sporulated Eimeria coquelinae oocyst

countries (Kutzer \& Frey, 1976; Nickel \& Gottwald, 1979; Soveri \& Valtonen, 1983; Allgöwer, 1992; Shimalov, 2001), Graphidium strigosum was rarely found in the present study $(3.9 \%)$; this is probably related to the lack of wild rabbits (Broekhuizen \& Kemmers, 1976).

Comparison of infection found both in the animals and faecal samples show that the highest rate of discrepancies was observed in Trichuris leporis. This can be due to the great number of both Trichuris larvae and young specimens found in the intestines of hares in the winter season. A very small number of tapeworms eggs (Anoplocephalidae) were recorded in the faeces $(0.87 \%)$, no tapeworms were found in the intestines of the hares.

Strongyloides sp. is one of the many tiny parasites that can be easily overlooked. These parasites can only be found using a microscope, as shown through our experience with parasites of sheep (Langrova et al., 2008). However, results from coproscopical examinations show that Strongy-

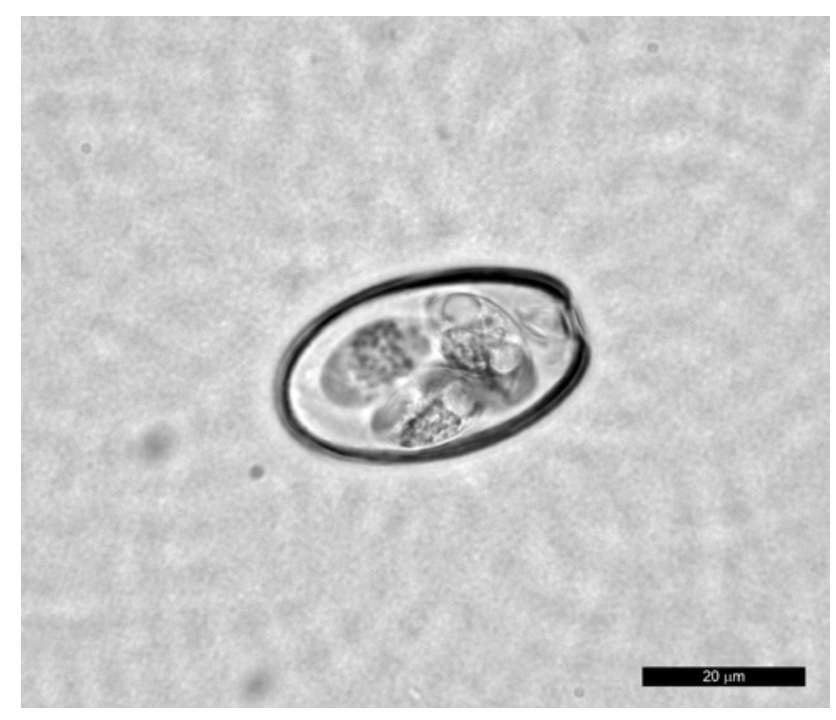

Fig. 5. The photomicrograph of sporulated Eimeria cabareti oocyst loides (most likely $S$. papillosus) is a relatively common parasite of lagomorphs.

The dynamics of exogenous parasitic stage excretion were monitored in the second year, from November 2009 to April 2009. One purpose of this investigation was to study the effects of the administration of anticcocidial supplementation in the diet; in December 2009, a one-time application of Robenidin hydrochloride $-66 \mathrm{mg}$ of the preparation per $1 \mathrm{~kg}$ of fodder mixture, $0.6 \mathrm{~kg}$ food/hare/day - was added to fodder.

As Fig. 1 demonstrates, this drug suppresses the intensity of infection for no more than three months however, it does not affect the prevalence of this parasite.

The paucity of the parasite community could be related to both the low and ever decreasing densities of hares in the Czech Republic, and also due to the excellent care of game hares in the nation's gamekeeper grounds (including veterinary care, winter fodder).

Coccidia are among the most potent pathogenic parasites of hares, and in combination with lung and digestive tract nematodes, they have become a major regulatory factor of the hare population (Chroust, 1984). In previous studies, the prevalence rates of coccidial infections in hares in the Czech Republic were very high, ranging between $92.5 \%$ and 100 \% (Ryšavý, 1954; Chroust, 1979, 1984; Jirouš, 1979; Pakandl, 1990) and likewise in hares from surrounding countries such as Germany, Austria or Poland: between $63.3 \%$ and $100 \%$ (Kutzer \& Frey, 1976; Haupt \& Hartung, 1976; Forstner \& Ilg, 1982; Algöwer, 1992; Böckeler et al., 1994; Pilarczyk et al., 2008). During coprological examination, oocysts of the following species were found: Eimeria coquelinae, E. cabareti, E. leporis, E. babatica, E. europea, E. pierrecouderti, E. macrosculpta, E. orbiculata and E. stefanski. Oocyst differentiation was performed according to Pellérdy (1956), Bouvier (1967), Levine and Ivens (1972), Pakandl (1990) and Aoutil et al. (2005). The species were named according to Aoutil et al. (2005), however, we determined differences in the shapes of some species. The shapes of Eimeria coquelinae as well as E. cabareti differed from their depictions in microphotographs and sketches by Aoutil et al. (2005). We observed the shape of Eimeria coquelinae which was ovoid and not short ellipsoid (according Aoutil et al., 2005) while the shape of E. cabareti was ellipsoid, and not ovoid (Figs 4 and 5). Our observation of the shapes of these coccidia species coincide with the microphotographs taken by $\mathrm{Pa}-$ kandl (1990).

This study confirms that coccidiosis is the most significant threat to game hares in the Czech Republic. Other species, especially Trichostrongylus retortaeformis and Trichuris spp. are a normal part of the parasite fauna of hares. However, we believe that these parasites significantly affect neither the health nor the population of hares.

\section{Acknowledgements}

The authors are grateful to Brian Kavalir (Ontario Canada) for his proofreading services. 


\section{References}

ALlGÖWER, R. (1992): Der Parasitenbefall von Feldhasen aus der Oberrheinebene und seine intraspezifische Bedeutung. $Z$. Jagdwiss., 38: 116 - 127. DOI: 10.1007/BF02286501

Aoutil, N., Bertani, S., Bordes, F., SnOunou, G., Chabaud, A., LANDAU, I. (2005): Eimeria (Coccidia: Eimeridea) of hares in France: Description of new taxa. Parasite, 12: 131 - 144

Böckeler, W., MoKhtari-Derakhshan, F. L., Pecher, W. T. (1994): Zur Parasitenbürde des Feldhasen (Lepus europaeus) in Schleswig-Holstein. Z. Jagdwiss., 40: 22 29. DOI: $10.1007 / \mathrm{BF} 02241502$

Bordes, F., Langand, J., Feliu, C., Morand, S. (2007): Helminths communities of an introduced hare (Lepus granatensis) and a native hare (Lepus europaeus) in southern France. J. Wildl. Dis., 43: 747 - 751

Bouvier, G. (1967): Les Coccidies rencontrées en Suisse chez le lièvre gris (Lepus europaeus). Ann. Parasitol. Hum. Comp., 42: $551-559$

Broekhuizen, S., Kemmers, R. (1976): The stomach worm, Graphidium strigosum (Dujardin) Railliet and Henry, in the European hare, Lepus europaeus Pallas. In: PIELOWSKI, Z., PUCEK, Z. (Eds) Ecology and Management of European Hare Populations, Polish Hunting Association, Warsaw, pp. $157-171$

CROFTON, H. D. (1946): The ecology of immature phases of Trichostrongyle nematodes. II. The effect of climatic factors on the availability of the infective larvae of Trichostrongylus retortaeformis to the host. Parasitology, 39: 26 - 38. DOI: 10.1017/S0031182000083517

DubinskÝ, P., VAsilkovÁ, Z., HuRníKOVÁ, Z., MiterPÁKOVÁ, M., SlAMEČKA, J., JuRČÍK, R. (2010): Parasitic infections of the European brown hare (Lepus europaeus Pallas, 1778) in south-western Slovakia. Helminthologia, 47: 219 - 225. DOI: 10.2478/s11687-010-0034-7

EYSKER, M., KOOYMAN, F. N. J. (1993): Notes on necropsy and herbage processing techniques for gastrointestinal nematodes of ruminants. Vet. Parasitol., 46: $205-213$. DOI:10.1016/0304-4017(93)90059-V

Fettinger, V., SMulders, F. J. M., Lazar, P., OMurtag, I., PAUlsen, P. (2010):Leison in thighs from hunted Brown Hares (Lepus europaeus) and microflora under vakuumpackaging storage. Eur. J. Wildl. Res., 56: 943 - 947

FORSTNER, M., ILG, V. (1982): Untersuchungen über die Endoparasiten der Feldhasen (Lepus europaeus). Z. Jagdwiss., 28: 169 - 177. DOI: 10.1007/BF02241927

HAUPT, W., HARTUNG, J. (1976): Endoparasitenbefall der Hasen aus der Umgebung von Leipzig. Monatsh. Veterinarmed., 32: $339-341$

Chroust, K. (1979): A contribution to the determination and species representation of hare coccidia. Veterinártví, 29: $507-509$

Chroust, K. (1984): Dynamics of coccidial infection in free living and cage-reared european hares. Acta Vet. Brno, 53: $175-182$
JIROUŠ, J. (1979): Some observations of hare coccidia from central and nortwestern Bohemia. Lesnictví, 25: 1015 1027

Kotrlá, B., ČERnÝ, V., KOTRlÝ, A., MinÁŘ, J., RYŠAVÝ, B., ŠEBEK, Z. (1984): Parasites of Wild Animals. Prague, Czech Republic, Academia, 191 pp.

Kutzer, E., Frey, H. (1976): Die Parasiten der Feldhasen (Lepus europaeus) in Östereich. Berl. Munch. Tierarztl. Wochenschr., 89: $480-483$

LANGROVÁ, I., MAKOVCOVÁ, K., VADLEJCH, J., Jankovské, I., PetrtÝl, M., Fechtner, J., KeIL, P., LytVynets, A., BorkovcovÁ, M. (2008): Arrested development of sheep strongyles: onset and resumption under field conditions of Central Europe. Parasitol. Res., 103: 387 - 392. DOI: 10.1007/s00436-008-0984-6

LEVINE, N. D. (1980): Nematode Parasites of Domestic Animals and of Man. 2nd Edition, Mineapolis, Minnesota, Burgess Publishing Company, 477pp.

LEVINE, N. D., IVENS, V. (1972): Coccidia of the Leporidae. J. Protozool., 19: 572 - 581

MilÁČEK, P., VÍTOVEC, J. (1985): Differential staining of cryptosporidia by aniline-carbol-methyl violet and tartrazine in smears from faeces and scraping of intestinal mucosa. Folia Parasitol., 32: 50

Nickel, S., GotTwald, A. (1979): Beiträge zur Parasitenfauna der DDR. 3. Mittleitung. Endoparasiten des Feldhasen (Lepus europaeus). Angew. Parasitol., 20: 57 - 62

PAKANDL, M. (1990): Some remarks on the prevalence and species composition of hare coccidia. Folia Parasitol., 37: $35-42$

PELLÉRDY, L. (1956): On the status of the Eimeria species of Lepus europaeus and related species. Acta. Vet. Acad. Sci. Hung., 6: $451-467$

PILARCZYK, B., BALICKA-RAMISZ, A., RAMISZ, A., CiEChANOWICZ, J. (2008): Preliminary studies on parasitic fauna of hares introduced on the Chrzaszczewska Island, West Pomerania. Wiad. Parazytol., 54: 159 - 161

RYŠAVÝ, B. (1954): A contribution to the recognition of indigenous and imported vertebrate coccidia. Českoslov. Parazitol., I: 131 - 173

Shimalov, V. V. (2001): Helminth fauna of the hare (Lepus europaeus Pallas, 1778) in the southern part of Belarus. Parasitol. Res., 87: 85. DOI: 10.1007/s004360000259

SOVERI, T., VALTONEN, M. (1983): Endoparasites of hares (Lepus timidus L. and L. europaeus Pallas) in Finland. $J$. Wildl. Dis., 19: 337 - 341

STATSOFT, INC. (2009). STATISTICA (data analysis software system), version 9.0. www.statsoft.com

Strauss, E., Pohlmeyer, K. (2001): Zur Populationsökologie des Feldasen. In Wo liegt der hase im pfeffer. Naturschutz und rote liste? - Jagd und Hege, NUA-Serminarbericht Band 7, 2001. Natur- und Umweltschutzakademie NRW (Hrsg.), pp 5 - 20

Wetzel, R. (1951): Vebesserte McMaster - Kammer zum Auszählen von Wurmeiern. Tierarztl. Umsch., 6: 209-210

ACCEPTED MAY 4, 2012 